\title{
GENDER AND GRADUATE ECONOMICS EDUCATION IN THE US
}

\author{
David Colander and Jessica Holmes
}

\begin{abstract}
This paper reports on the findings of a survey of top economics graduate schools as they relate to women and men. The results provide strong evidence that at these top graduate schools, women graduate students are less integrated in their economic disciplines than are male graduate students. In the second part of the paper, this paper relates those findings to alternative theories as to why this is the case. This paper concludes by suggesting that the emphasis on theoretical studies in the current core of the graduate economics program can be seen as a type of hazing process that seems to have a significant cost since many women (and men) with great creative promise are discouraged from continuing in economics and do not benefit nearly as much as they would have from more policy-driven core courses.
\end{abstract}

\author{
KEYWORDS \\ Education, gender division of labor, gender roles
}

JEL Codes: A14, A23, I2

\begin{abstract}
I was surprised that the level of emotional torture that I experienced in the first year was worse than anything I expected. I remember one of my advisors telling me that it took her five years to get over the damage done to her in grad school. There are just not words to express it.
\end{abstract}

—Female economics graduate student

In a recent study of graduate education, David Colander (2005) reported on findings at top US graduate schools in economics. Colander surveyed students at top economics graduate programs (Princeton, Harvard, Yale, MIT, Columbia, Stanford, and Chicago). It was a follow-up on the Colander-Klamer survey (David Colander and Arjo Klamer 1987) that was done in the 1980 s to gain insight into the nature of graduate economic education. In the recent survey, there were 231 respondents and the response rate was about 27 percent, approximately the same as the previous survey. Women made up 29 percent of the respondents. The 
survey took students about an hour to complete and was followed up by interviews with students. ${ }^{1}$ In his report, Colander (2005) focused on differences among schools and aggregate results. In this paper we report and discuss results of that survey as they relate to differences between women and men in US graduate programs. These differences are of interest because they help us understand why women are underrepresented in the economics profession and give us insight into the charge that the structure of US graduate economics education marginalizes women.

While the results are for top US economic graduate schools, the central role that these schools play in training economists from all over the world (e.g., more than 60 percent of our sample is international) make the results relevant to a broader international audience. The survey results provide strong evidence that at these top graduate schools women are less satisfied with their graduate economics education and are less integrated into the academic economics profession than male graduate students. It also suggests that an important reason why women are less satisfied is the structure of the core courses in US graduate economics training, which involves what can be thought of as a selection mechanism designed to separate out those interested in abstract theory from those interested in applied policy. For those students interested primarily in applied policy, this selection mechanism can be seen as a hazing process that such students must survive in order to work as an applied policy economist.

In this paper, we report gender differences in the demographics, satisfaction, and academic integration of economics graduate students. In response to these data we suggest three hypotheses: The first is the mentoring/role model hypothesis, which holds that women are less satisfied and less integrated into academia because they lack role models and mentors. (The percentage of women professors at all these US schools is small as it is throughout the economics profession.) The second, the mismatch hypothesis, suggests that female students are less satisfied and less integrated because they are not as well matched to the type of economics currently being taught in US graduate schools that deemphasizes applied and policy-related economics. The third explanation, the stereotype threat hypothesis, posits that women's individual performance, opportunity, and satisfaction in economics graduate programs suffers because women as a group have been previously stereotyped as being less capable than men.

\section{THE RESULTS}

The survey and interview results yielded a wealth of information about the graduate students' backgrounds, interests, and perceptions of their 
experiences in these top programs. In Table 1, we report the differences in the demographic profiles of male and female $\mathrm{PhD}$ students at top institutions.

As you can see, nearly half (48 percent) of the women in the top economics programs are US citizens compared to only about a third of men (34 percent). Women, however, come from markedly more diverse ethnic backgrounds than men; only 37 percent of females report being white compared to 55 percent of males (female graduate students are more likely to be African American/black or South Asian). There are also statistically significant gender differences in parents' educational backgrounds: compared to men, women are more than four times as likely to have a mother with a $\mathrm{PhD}$ (25 percent versus 6 percent) and more than twice as likely to have a father with a $\mathrm{PhD}$ (32 percent versus 15 percent), and women's fathers were far more likely to be liberal than men's fathers (38 percent versus 25 percent).

Beyond these demographic differences, their reasons for pursuing higher degrees in economics differ. Table 2 provides some insight into the reasons men and women chose to attend graduate school. ${ }^{2}$

Slightly more men than women ( 72 percent of men and 63 percent of women) report that the compatibility of economics with their intellectual interests was a major factor in their decision to attend graduate school. Women were more likely than men to cite acceptance by a top graduate program (68 percent versus 53 percent of men), high grades in economics courses (39 percent versus 33 percent), and advice by undergraduate faculty (38 percent versus 30 percent) as important factors in their decision to pursue graduate study. While the only gender difference that is statistically significant is "acceptance by a good graduate school"

Table 1 Demographics of $\mathrm{PhD}$ candidates in economics

\begin{tabular}{lrrc}
\hline & Male & Female & Difference \\
\hline US Citizen & $33.95 \%$ & $47.69 \%$ & $13.74(7.10)^{*}$ \\
Ethnicity & & & \\
White & $54.66 \%$ & $36.92 \%$ & $17.74(7.28)^{* *}$ \\
African American/black & $0.00 \%$ & $3.08 \%$ & $3.08(1.37)^{* *}$ \\
Hispanic & $7.45 \%$ & $4.62 \%$ & $2.84(3.67)$ \\
South Asian & $3.73 \%$ & $10.77 \%$ & $7.04(3.40)^{* *}$ \\
East Asian & $6.83 \%$ & $10.77 \%$ & $3.94(3.99)$ \\
Middle Eastern & $.62 \%$ & $1.54 \%$ & $.92(1.38)$ \\
Mother has PhD & $6.17 \%$ & $24.62 \%$ & $18.44(4.53)^{* * *}$ \\
Father has PhD & $14.81 \%$ & $32.31 \%$ & $17.49(5.76)^{* * *}$ \\
Father's politics - liberal & $24.07 \%$ & $38.46 \%$ & $14.39(6.57)^{* *}$ \\
Mother's politics - liberal & $38.89 \%$ & $40.00 \%$ & $1.11(7.20)$ \\
\hline
\end{tabular}

$* * *$ denotes $\mathrm{p}<.01$; **denotes $\mathrm{p}<.05$; *denotes $\mathrm{p}<.10$ in two-tailed t-tests for gender differences. Standard errors are in parentheses. 
$(\mathrm{p}<.05)$, the pattern in responses suggests that women are more likely to base their decision to attend graduate school on external factors.

Women's perceptions of their studies differ as well, and some of the most striking gender differences in the survey are presented in Table 3, which reports elements that students saw as very stressful. Women were more than twice as likely (52 percent versus 25 percent of men) to find coursework very stressful, more than three times as likely (23 percent versus 7 percent) to find doing the mathematics as very stressful, and almost three times as likely to find relationships with faculty as stressful (17 percent to 6 percent). Note that these differences are statistically significant at conventional levels. However, the higher level of stress did not carry through to all areas; women were far less likely to find their financial situation stressful. In the other comparisons shown in Table 3, the responses of men and women were almost the same.

Table 2 Reasons given for the decision to attend graduate school

\begin{tabular}{lrrr}
\hline & Male & Female & Difference \\
\hline $\begin{array}{l}\text { Economics seemed the most relevant field } \\
\text { given my intellectual interests }\end{array}$ & $71.60 \%$ & $63.08 \%$ & $8.53(6.79)$ \\
Enjoyed undergraduate classes & $61.11 \%$ & $56.92 \%$ & $4.19(7.22)$ \\
Acceptance by a good graduate school & $52.47 \%$ & $67.69 \%$ & $15.22(7.23) * *$ \\
Desire to engage in policy formation & $48.77 \%$ & $53.85 \%$ & $5.08(7.37)$ \\
Good grades in economics classes & $33.33 \%$ & $38.46 \%$ & $5.13(7.02)$ \\
Advice of my undergraduate teachers & $30.25 \%$ & $38.46 \%$ & $8.21(6.89)$ \\
Wanted to get a job in academia and economics & $24.69 \%$ & $23.08 \%$ & $1.61(6.32)$ \\
$\quad$ seemed to offer the best possibility & $10.49 \%$ & $10.77 \%$ & $.28(4.53)$ \\
Political reasons & & &
\end{tabular}

$* *$ denotes $\mathrm{p}<.05$ in two-tailed $\mathrm{t}$-tests for gender differences. Standard errors are in parentheses.

Table 3 Elements of graduate school that have been "very stressful"

\begin{tabular}{lrrr}
\hline & Male & Female & Difference \\
\hline Coursework & $25.31 \%$ & $52.31 \%$ & $27.00(6.70)^{* * * *}$ \\
Financial situation & $11.11 \%$ & $1.54 \%$ & $9.57(4.03)^{* *}$ \\
Relationship with faculty & $6.17 \%$ & $16.92 \%$ & $10.75(4.21)^{* *}$ \\
Relationship with students & $.62 \%$ & $3.08 \%$ & $2.46(1.68)$ \\
Doing the mathematics & $6.79 \%$ & $23.08 \%$ & $16.29(4.57)^{* * *}$ \\
Finding a dissertation topic & $26.54 \%$ & $30.77 \%$ & $4.23(6.60)$ \\
Maintaining a meaningful life outside school & $20.37 \%$ & $23.08 \%$ & $2.71(6.02)$ \\
Conflict between course content and & $14.81 \%$ & $16.92 \%$ & $2.11(5.32)$ \\
$\quad$ your interests & & & \\
\hline
\end{tabular}

$* * *$ denotes $\mathrm{p}<.01 ; * *$ denotes $\mathrm{p}<.05$ in two-tailed t-tests for gender differences. Standard errors are in parentheses. 
In the interviews with students about the survey, both male and female students stated that they did not believe that the differences were due to different abilities of women and men; the students' perception was that the women and men had equal abilities (David Colander 2007). ${ }^{3}$

Sometimes, information about student views can be gained from their choices about where they spend their time when they are not studying. Table 4 looks at other activities in which graduate students are involved to see if that was the case. Although none of the gender differences in Table 4 are statistically significant, there seems to be a consistent difference in the responses of women and men. Women are slightly less likely than men to have a research assistantship (28 percent versus 33 percent of men) or a teaching assistantship (38 percent versus 43 percent) and are less likely to be engaged in the writing of scholarly papers for publication (42 percent versus 49 percent) or professional consulting (6 percent versus 9 percent). ${ }^{4}$ Women are, however, slightly more likely than men to do volunteer work (14 percent versus 10 percent) and report engagement in "other significant activities", (20 percent versus 17 percent). ${ }^{5}$

One of the most important choices that a graduate student makes is deciding on a dissertation topic. Table 5 looks at the major factors behind

Table 4 Activities engaged in, besides studying

\begin{tabular}{lrrr}
\hline & Male & Female & Difference \\
\hline Research assistantship & $33.33 \%$ & $27.69 \%$ & $5.64(6.85)$ \\
Teaching assistantship & $42.59 \%$ & $38.46 \%$ & $4.13(7.26)$ \\
Writing scholarly papers for publication & $49.37 \%$ & $41.54 \%$ & $7.84(7.34)$ \\
Consulting & $8.64 \%$ & $6.15 \%$ & $2.49(3.98)$ \\
Volunteer work & $10.49 \%$ & $13.85 \%$ & $3.35(4.69)$ \\
Political work & $3.09 \%$ & $3.08 \%$ & $.01(2.55)$ \\
Sports & $33.95 \%$ & $35.38 \%$ & $1.43(7.00)$ \\
Other significant activities & $16.67 \%$ & $20 \%$ & $3.33(5.61)$ \\
\hline
\end{tabular}

Standard errors in parentheses.

Table 5 Major factor in choice of dissertation topic

\begin{tabular}{lrrr}
\hline & Male & Female & Difference \\
\hline $\begin{array}{l}\text { Suggestion of a teacher } \\
\begin{array}{l}\text { Desire to understand some economic } \\
\text { phenomenon }\end{array}\end{array}$ & $66.69 \%$ & $10.77 \%$ & $7.68(3.26)^{* * *}$ \\
$\begin{array}{l}\text { Desire to get the dissertation done and } \\
\text { thus the feasibility of the topic }\end{array}$ & $10.49 \%$ & $16.92 \%$ & $6.43(4.83)$ \\
$\begin{array}{l}\text { The application of certain mathematical } \\
\text { or econometric techniques }\end{array}$ & $2.47 \%$ & $3.08 \%$ & $.61(2.37)$ \\
\hline
\end{tabular}

**denotes $\mathrm{p}<.05$ in two-tailed t-tests for gender differences. Standard errors are in parentheses. 
students' choices and shows that additional gender differences emerge. While both men and women overwhelmingly choose topics that enhance the understanding of some economic phenomenon (67 percent and 55 percent, respectively), women are significantly more likely than men (11 percent versus 3 percent) to choose a topic based on the suggestion of a teacher.

Students' fields of interest also reveal gender differences in fields, as reported in Table 6. (Respondents could indicate more than one field as being “of great interest.') Overall, it appears that men are much more likely to be interested in theoretical fields while women are considerably more likely to be interested in applied fields.

Table 7 further highlights the gender differences in preferred economic topics. Respondents were asked to rank different types of articles according to their interests. While the majority of both men and women

Table 6 Fields "of great interest"

\begin{tabular}{lrrr}
\hline & Male & Female & Difference \\
\hline Micro theory & $41.98 \%$ & $18.46 \%$ & $23.51(6.87)^{* * *}$ \\
International trade & $17.90 \%$ & $23.08 \%$ & $5.18(5.82)$ \\
Labor economics & $27.78 \%$ & $41.54 \%$ & $13.76(6.80)^{* *}$ \\
Urban economics & $9.26 \%$ & $16.92 \%$ & $7.66(4.67)^{*}$ \\
History of thought & $11.11 \%$ & $4.62 \%$ & $6.50(4.25)$ \\
Macro theory & $35.19 \%$ & $29.23 \%$ & $5.95(6.95)$ \\
Public finance & $22.84 \%$ & $27.69 \%$ & $4.85(6.31)$ \\
Economic development & $38.27 \%$ & $40.00 \%$ & $1.73(7.18)$ \\
Political economy & $26.54 \%$ & $18.46 \%$ & $8.08(6.30)$ \\
Econometrics & $25.93 \%$ & $13.85 \%$ & $12.08(6.10) * *$ \\
Money and banking & $24.69 \%$ & $12.31 \%$ & $12.38(5.97) * *$ \\
Law and economics & $16.67 \%$ & $10.77 \%$ & $5.90(5.25)$ \\
Comparative economic systems & $8.64 \%$ & $9.23 \%$ & $.59(4.18)$ \\
\hline
\end{tabular}

$* * *$ denotes $\mathrm{p}<.01 ; * *$ denotes $\mathrm{p}<.05$; *denotes $\mathrm{p}<.10$ in two-tailed t-tests for gender differences. Standard errors are in parentheses.

Table 7 Most interesting type of article

\begin{tabular}{lrrr}
\hline & Male & Female & Difference \\
\hline Pure theory (e.g., Journal of Economic Theory) & $12.42 \%$ & $3.08 \%$ & $9.35(4.33)^{* *}$ \\
Pure econometrics (e.g., Econometrica) & $5.60 \%$ & $1.54 \%$ & $4.05(3.02)$ \\
Combination of theory and econometrics & $68.32 \%$ & $60 \%$ & $8.32(6.97)$ \\
$\quad$ (e.g., AER) & & & \\
Applied economics (e.g., Brookings Papers) & $14.91 \%$ & $33.85 \%$ & $18.94(5.81)^{* * *}$ \\
Non-conventional economics (e.g., Review of & $2.48 \%$ & $1.54 \%$ & $.95(2.17)$ \\
$\quad$ Radical Political Economy) & & & \\
\hline
\end{tabular}

$* * *$ denotes $\mathrm{p}<.01 ; * *$ denotes $\mathrm{p}<.05$ in two-tailed t-tests for gender differences. Standard errors are in parentheses. 
ranked American Economic Review type articles that balance theory and econometrics first (68 percent and 60 percent respectively), women were more likely than men to rank an applied economics journal first ( 34 percent of women versus 15 percent of men) while men were more likely than women to rank a pure theory journal first (12 percent of men versus 3 percent of women).

One of the questions that generated a lot of discussion in the aggregate study was what placed students on the fast track, which most students interpreted as meaning as leading them to the top of the profession. Table 8 reports the percentage of respondents who claim various characteristics to be "very important" in increasing the likelihood that students are placed on the fast track. In general, there are not large differences in the responses of women and men. The only statistically significant difference emerges in the relative importance of professional networks. While only 30 percent of men describe the ability to make connections with prominent professors as "very important," 42 percent of women find these connections to be a "very important" entrée to the fast track. We discuss potential explanations for this interesting finding below.

Table 9 reports the respondents' career plans. (Students were permitted to give more than one answer.) Women and men have very different visions of where they will be both directly following graduate school and in the distant future. After graduate school, 62 percent of men compared to only 48 percent of women plan to pursue an academic career. In terms of their future goals, 66 percent of men envision themselves at a major university fifteen years after graduation. The comparable figure for women is only 42 percent. Women were significantly more likely than men to see their career paths leading to a liberal arts college, a major research institution, or an economic policy-making institution.

Table 8 Characteristics that students deem "very important" in increasing the likelihood that students are placed on the fast track

\begin{tabular}{lrrr}
\hline & Male & Female & Difference \\
\hline $\begin{array}{l}\text { Being smart in the sense that they are good at } \\
\quad \text { problem solving }\end{array}$ & $49.38 \%$ & $55.38 \%$ & $6.00(7.36)$ \\
Being interested in, and good at, empirical & $30.25 \%$ & $29.23 \%$ & $1.02(6.76)$ \\
$\quad$ research & & & \\
Excellence in mathematics & $30.86 \%$ & $29.23 \%$ & $1.63(6.78)$ \\
Being very knowledgeable about one particular & $36.42 \%$ & $32.31 \%$ & $4.11(7.04)$ \\
$\quad$ field & & & \\
Ability to make connections with prominent & $29.63 \%$ & $41.54 \%$ & $11.91(6.89)^{*}$ \\
$\quad$ professors & & & $.28(4.53)$ \\
A broad knowledge of the economics literature & $10.49 \%$ & $10.77 \%$ & $.03(4.27)$ \\
A thorough knowledge of the economy & $9.26 \%$ & $9.23 \%$ & .03 \\
\hline
\end{tabular}

$*$ denotes $\mathrm{p}<.10$ in two-tailed t-tests for gender differences. Standard errors in parentheses. 
Perhaps one of the most important issues in deciding whether women's experience in graduate school differs from men's is to be found in their satisfaction with their experience. Table 10 considers the gender differences in satisfaction with graduate school. In this summary measure, there are statistically significant differences between men and women, with women far less satisfied with their graduate experiences than men. Specifically, 83 percent of men would choose to attend graduate school in economics again compared to only 60 percent of women. Perhaps even more telling, 70 percent of men would attend the same graduate school compared to 52 percent of women.

Several other results from this survey are worthy of mention. In answer to a question about how students saw their own views changing over the course of their studies:

- Among women, 28 percent strongly agreed that neoclassical economics is relevant to economic problems both before and after graduate school, while the proportion of men who agreed rose from 40 percent to 50 percent.

- On the proposition that economics is the most scientific discipline among the social sciences: men's views remained approximately

Table 9 Career plans

\begin{tabular}{lrrr}
\hline & Male & Female & Difference \\
\hline $\begin{array}{l}\text { Will pursue an academic career after } \\
\text { graduate school }\end{array}$ & $62.35 \%$ & $47.69 \%$ & $14.65(7.21)^{* *}$ \\
Career path in fifteen years & & & \\
Major university & $66.05 \%$ & $41.54 \%$ & $24.51(7.07)^{* * *}$ \\
Good liberal arts college & $6.79 \%$ & $13.85 \%$ & $7.06(4.15)^{*}$ \\
Major research institution & $14.81 \%$ & $26.15 \%$ & $11.34(5.62)^{* *}$ \\
Economic policy-making institution & $14.81 \%$ & $26.15 \%$ & $11.34(5.62)^{* *}$ \\
Private sector & $5.56 \%$ & $6.15 \%$ & $.60(3.43)$ \\
Other & $9.88 \%$ & $10.76 \%$ & $.89(4.44)$ \\
\hline
\end{tabular}

$* * *$ denotes $\mathrm{p}<.01 ; * *$ denotes $\mathrm{p}<.05$; *denotes $\mathrm{p}<.10$ in two-tailed t-tests for gender differences. Standard errors in parentheses.

Table 10 Satisfaction with graduate school

\begin{tabular}{lccc}
\hline & Male & Female & Difference \\
\hline $\begin{array}{l}\text { If you had to do it over again, would you } \\
\text { go to graduate school in economics? }\end{array}$ & $82.72 \%$ & $60.00 \%$ & $22.72(6.09)^{* * *}$ \\
$\begin{array}{l}\text { (Percent responding yes) } \\
\text { Would you go to the same graduate school? } \\
\text { (Percent responding yes) }\end{array}$ & $70.37 \%$ & $52.31 \%$ & $18.06(6.92)^{* * *}$ \\
\hline
\end{tabular}

***denotes $\mathrm{p}<.01$ in two-tailed t-tests for gender differences. Standard errors in parentheses. 
constant, with 51 percent strongly agreeing before graduate school and 48 percent strongly agreeing after, while women's views started much lower, at 29 percent before but rose to 56 percent after.

- On the proposition that we can draw a sharp line between positive and normative economics: men's views fell slightly, with 16 percent strongly agreeing that we can draw a sharp line before and 14 percent after, while women's views started at 13 percent strongly agreeing but fell to 7 percent after.

\section{DISCUSSION AND INTERPRETATION OF RESULTS}

The results presented in this paper provide strong evidence that even at these top graduate schools women are less integrated into the economics discipline than men. Women are less satisfied with their graduate economics education, experience more stress than their male counterparts, and are less likely to be planning a career in academia. Thus, a special concern about women's role in economics seems warranted. The results also suggest that the foundation for the leaky pipeline that has characterized the trend of women's participation in economics, which declines at higher levels as they fail to move up the ladder (Shulamit Kahn 1995; Donna Ginther and Shulamit Kahn 2004), is established at least as early as graduate school. ${ }^{6}$

Unfortunately, the results of this survey do not explain why women are less integrated, but there are a number of possibilities, not necessarily mutually exclusive. The following section relates our findings to three explanations that have been suggested in the literature.

\section{The mentoring/role model explanation}

The explanation that has been most discussed in the literature to explore why women are less integrated into the economics discipline might be called the mentoring/role model explanation. This may be characterized as a hysteresis problem. ${ }^{7}$ According to this argument, the reason women academics in traditionally male fields are less integrated into their departments and disciplines is because they do not enjoy the same relationships with mentors and role models and do not have the same access to professional networks as their male counterparts (John McDowell and Janet Smith 1992; Shulamit Kahn 1993, 1995; John McDowell, Larry Singell Jr., and Mark Slater 2006).

Substantial support for this explanation exists in the literature. In an early study, Elyse Goldstein (1979) found that scholars' subsequent academic productivity is greater when protégé and mentor are of the same sex. Similarly, Helen Berg and Marianne A. Ferber (1983) reported in their survey of graduate students at the University of Illinois at 
Urbana-Champaign that male graduate students are more likely to form strong relationships with male faculty members while female graduate students are more likely to establish strong relationships with female faculty members. In another study, Lucia Gilbert, June M. Gallessich, and Sherri L. Evans (1983) found that female graduate students who identified women professors as role models viewed themselves as more careeroriented and confident than female students identifying with male role models. David M. Marx and Jasmin R. Roman (2002) also found that highly motivated and mathematically talented women perform considerably better on math exams when a highly competent female (i.e., female role model) instead of an equally competent male administered the test.

Two studies have looked specifically at the experiences of economics students. David Neumark and Rosella Gardecki (1998) found that both dropout rates and time spent in graduate school by female economics students are lower in departments with a larger proportion of female faculty (although they find no evidence that initial job placements are improved by the addition of female faculty). ${ }^{8}$ In addition, Paula Haslehurst, Sandra Hopkins, and Michael Thorpe (1998) found in their survey of both undergraduate and graduate economics students in Australia that 40 percent of women agree that a lack of role models is a reason why they would not consider a career in academia. Only 28 percent of men found lack of role models to be an obstacle. Not surprisingly, their study showed that the greater the proportion of women faculty in the department, the less important was the lack of role models in the decision to consider an academic career.

A common suggestion is that women are more likely than men to look for external evidence of their own competence and thus are more strongly influenced by others' evaluations. Studies by psychologists have shown that women are indeed more responsive to external feedback and outside validation than men (Tomi-Ann Roberts 1991; Tomi-Ann Roberts and Susan Nolen-Hoeksema 1994). Furthermore, evidence suggests that without such feedback, women are more likely to attribute poor performance to lack of ability while men are more likely to attribute poor performance to bad luck (Kay Deaux and Timothy Emswiller 1974; Kay Deaux and Elizabeth Farris 1977; Bernard E. Whitley, Jr., Maureen C. McHugh, and Irene H. Frieze 1986). Women may thus derive greater benefits than men from positive interactions and encouraging feedback from mentors.

Research also suggests that women lack access to the same professional networks as men. For example, McDowell and Smith (1992) find that both males and females are more likely to collaborate with economists of the same gender. In fact, they find that female economists are less likely to coauthor in general, although the reasons for this difference are not clear. Male economists also tend to cite men more often than women do, while 
female economists tend to cite women more often than men do (Marianne Ferber 1988). To the extent that colleagues within professional networks are more likely to collaborate, exchange working papers, invite one another to seminars and conferences, and cite each other's work from graduate school on, women will be less integrated into the research network. Hence, they will have less of an impact on the profession and will be at a disadvantage in job placement, publications, and promotions.

A number of the findings of our current study are consistent with the mentoring/role model explanation. For example, as mentioned earlier in this paper, women are more than four times as likely to have a mother with $\mathrm{a} \mathrm{PhD}$ and more than twice as likely to have a father with a $\mathrm{PhD}$ compared to men. For women, PhD-educated parents seem to be serving as strong role models and mentors, perhaps substituting for the role models and mentors that more often exist for men in the economics field. Interestingly, as indicated by their responses to questions about their reasons for applying for graduate school and their selection of a dissertation topic, women seem to be more receptive to mentorship, which they do not seem to be finding in these departments.

The differences in choice of field between men and women may also be related to this role model explanation. For example, the higher percentage of women in labor economics is often explained by the attention given to issues of gender and discrimination. While this may indeed be the case, it is also likely that as more women began working in labor, other women were attracted to the field because of the relative abundance of female role models and mentors.

Another of this study's findings is the higher level of stress that women students felt about their relationship with faculty. The fact that women are almost three times more likely than men to report stressful relationships with faculty fits easily with the explanation that there is a lack of female mentors and role models in economics. Additionally, women are less likely than men to have research and teaching assistantships and to engage in scholarly writing and professional consulting; this suggests that even in graduate school, women are not as well integrated in their departments and the discipline as their male counterparts. Overall, the fact that women were less satisfied with their graduate experience and were less likely to say they would do it over again, also suggests a degree of alienation from the program that is consistent with a lack of mentoring and role models.

The comments in the free response sections in the survey further support the role model/mentoring argument. While both women and men cited social isolation and lack of faculty support as primary reasons for disliking graduate school and saying they would not do it over again, women were more likely to say that than men. During an interview, one woman specifically said, "I wonder if I might fit into a smaller program with a stronger mentor relationship between faculty and student." A 
disproportionate number of women also "felt out of place" and "lost." They stated that they disliked the "lack of support and connection between grad students and faculty," the "little social interaction among people," and the "weak advising culture" in graduate school. During the interviews, one of the women summed it up in the following way: "The guys who leave the program seem to leave because they have outside earning opportunities that they think are greater. Women tend to leave because of the program.",

As already suggested, there may be other explanations as well. Men might be less willing than women to admit to poor relationships with faculty or that graduate school was a mistake. It is also possible that faculty simply give preferential treatment to male graduate students when it comes to supervising theses, assigning research assistantships, and securing job placements. The composite of available literature and survey responses suggest mentoring issues might be a plausible factor in women's dissatisfaction with their graduate economics studies.

\section{The mismatch explanation}

Another possible explanation for why women students are not well integrated into graduate school and for why they find graduate school in economics more stressful and less enjoyable is what might be called the mismatch explanation. One possible explanation for this mismatch might be that top graduate schools employ a subtle type of affirmative action in recruiting both women and US students.

In interviews with students, we found that students have the perception that admission committees exhibit a preference for US students, although we found no hard evidence that that is the case. In the interviews students also suggested that many believed affirmative-action recruiting was taking place for female students, which makes US female students a double minority. (Ginther and Kahn [2004] also found evidence of such affirmative action for women recruited at top schools.) If that is so, then at the margin, such students may be less matched to the economics discipline, even though on paper they are every bit as qualified.

The issue is one of goals. Graduate admissions committees may choose students whose goals are aligned with their goals; that is, they may choose people who want to write academic articles and conduct research at a PhD-granting institution. When a student doesn't share those goals, the admission committees tend not to choose him or her, however bright he or she may be. If, however, the admissions committees are trying to increase the percentage of women and US students in their programs, they may admit women and US students who are less likely to share those goals. ${ }^{9}$ Some of the responses from the survey support this explanation, such as the lower relevance women report for choosing to study economics because it 
fit their intellectual interests (72 percent of the men compared to 63 percent of the women said that their intellectual interest in economics was very important in choosing economics). The greater importance for women of being accepted at a top graduate school as a reason for going to graduate school (68 percent of the women, but only 53 percent of the men) also supports this explanation, since it suggests that the women in these schools considered other options than studying graduate economics as acceptable alternatives more than the men did.

A second possible explanation for the mismatch is the highly competitive nature of the economic academic research career for which schools concentrate their training. (The assistant professor pool at highly competitive graduate programs is sometimes called the "barracuda pool.") Individuals who are less comfortable with that highly competitive system will be less comfortable with the economic academic career than others. Two recent studies by Uri Gneezy, Muriel Niederle, and Arlo Rustichini (2003) and Uri Gneezy and Arlo Rustichini (2004) found that women's performance declines as the competitiveness of the environment increases, while men's performance is enhanced. Since graduate schools are preparing students for an often highly competitive academic research career, women, on average, may find the academic research focus of graduate education a less desirable match to their interests than a graduate economic education focused more on applied policy economics.

A number of results from the survey support the mismatch explanation:

- The greater stress in coursework and math that women experience.

- Women's lower satisfaction with graduate school (83 percent of men would attend a graduate program in economics again compared to only 60 percent).

- Women's lower likelihood of pursuing an academic career after graduate school (i.e., 62 percent of men plan to pursue an academic career compared to only 48 percent of women).

- The greater importance women attach to policy as a reason for going into economics (54 percent of women compared to 49 percent of men).

- Women's preference for applied research and men's preferences for theoretical research; when asked to rank articles according to their interest, 18 percent of men ranked either pure theory (cf. Journal of Economic Theory) or pure econometrics (cf. Econometrica) articles first, compared to only 5 percent of women. Similarly, 15 percent of men ranked applied economics (cf. Brookings Papers) articles first compared to a much higher 34 percent of women.

- Women's career goals were not well-supported by the faculty at these top programs; women were more likely to express interest in working at a liberal arts college (14 percent of women versus 7 percent of 
men) or an economic policy-making institution (26 percent of women versus 15 percent of men), and neither goal was well-supported by faculty.

The women's responses in interviews underscored this divide. One respondent said: "If you openly manifest that you're not sure about pursuing academia, they wouldn't support you at all." Her feelings were echoed by another who said: "Students definitely have to have a lot of enthusiasm for academia if they want the faculty to spend time with them."

We should emphasize that neither of these explanations for the mismatch suggests that selecting students involves a misunderstanding of overall ability; all students attending these programs at top universities are very bright individuals with a wide variety of options for their futures, many of which offer much higher pay than going to graduate school. Instead, the mismatch explanation concerns how well students fit with the program. As Colander (2007) discusses, top graduate programs are designed to prepare students for academic research careers rather than to solve policy issues. It might be that although women graduate students are, on all objective measurable standards, equal to male students, these women graduate students are less matched to the emphasis on academics placed by the institutional structure of the economics discipline. While women want to study economics, they are less likely than men to feel comfortable with the way it is currently being taught. They want more policy relevance and real world application and less technique and theory for technique and theory's sake.

To gain more insight into this mismatch explanation, we looked at a breakdown of the survey results by both gender and US citizenship. Table 11 illustrates the gender differences by international/ domestic status.

If there is indeed a mismatch due to affirmative action, we would expect to find large differences between international men and US women, with US women filling a "double minority" role. As Table 11 shows, that is what we find; the two groups are on opposite ends of the spectrum on course and mathematics stress, and on whether they say they would attend graduate school over again. We suspect that the mismatch is more prevalent for US women than it is for international women because there is a much greater disconnect between undergraduate and graduate economics education in the US than there is in other countries. As the following quotations suggest, American students (both male and female) feel under prepared relative to their international counterparts:

At least on average, the kind of training that we get as undergraduates is just not comparable. Mathematically, in terms of the 
GENDER AND US GRADUATE ECONOMICS EDUCATION

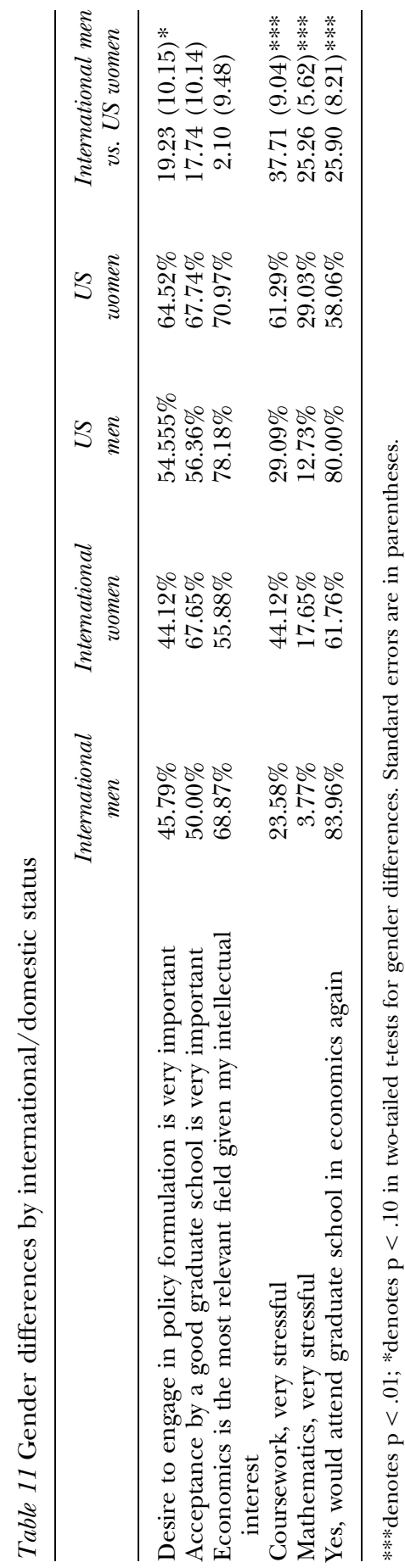

107 
depth, American students simply don't have the appropriate training... When you don't have that background you're just constantly catching up. That, I believe, is the curricular difference with other countries.

One foreign student I know told me that he took four noneconomic classes in his undergraduate education. In my whole undergraduate career I took a total of six economics classes. So there is certainly a structural break there.

Statistically significant differences in attitudes towards policy-making between the two groups also support the mismatch hypothesis; 46 percent of the international men but 65 percent of the US women saw the desire to engage in policy formulation as very important. ${ }^{10}$ Interestingly, international women indicate policy interest with the least frequency (44 percent), which serves to underscore that US women are a double minority because they suffer from the core curriculum's emphasis on theory more than their international female counterparts.

We want to be clear that there is no mismatch in ability or in the desire to study economics. In fact, in terms of intellectual interest 69 percent of the international men versus 71 percent of the US women saw economics as the most relevant field given their intellectual interest. So the real difference between the two groups is an interest in policy-formation rather than abstract theory, and for that reason, the emotional costs of graduate work in economics are high for US women.

\section{The stereotype threat explanation}

A third explanation for women fitting into the program less easily than men is what has been called the stereotype threat, a term used by social psychologists to refer to the heightened performance anxiety experienced by individuals who must perform a task for which their group is thought to not be qualified. ${ }^{11}$ A well-developed psychology literature has shown that the performance of fully capable individuals suffers in the presence of stereotype threat, even among those who do not believe the stereotype is true or applies to them.

For example, Claude Steele (1997) and Stephen Spencer, Claude Steele, and Diane Quinn (1999) demonstrate that mathematically talented women who were told that a difficult math test was biased against them performed worse on the test than women who were told that the test was "gender neutral." Similarly, Amy Bell et al. (2003) report underperformance by women taking engineering exams in the presence of lab-induced stereotype threat. The authors in each of these studies argue that the stereotype threat experienced by women in math-focused disciplines (like engineering, economics, and the physical sciences) may 
cause them to experience heightened anxiety and a sense of not belonging and thereby increase their tendency to drop out in order to avoid being stigmatized.

Our findings that more women than men report greater stress in coursework, mathematics, and relationships with faculty, as well as more dissatisfaction with the graduate school experience, are consistent with this explanation. However, there are other possible explanations; for example, it is possible that men and women experience the same levels of stress, but that men are less likely to admit it.

\section{THE LEAKY PIPELINE}

Any combination of these hypotheses could contribute to women's difficulty in their graduate school careers, and probably, the same factors follow those women as they pursue careers in academia. Cumulatively, the results of this study suggest that the discontent that leads to the leaky pipeline starts early. Female students don't fit what has become the academic model, which graduate schools emphasize and promote, as well as male students. While they may continue their academic careers after graduate school, the disenchantment with economics that begins in graduate school continues and leads to more and more choosing not to "play the academic game," as it is currently structured. This explanation is consistent with our findings but does not, however, account for the differences in economics and other fields in the nature of the leaky pipeline. Specifically, Ginther and Kahn (2004) discuss the possibility that affirmative action causes the mismatch that in turn results in the leaky pipeline but do not find it satisfying. They argue that this phenomenon is noticeably more prominent in economics than in all other technical fields that also follow affirmative action to increase the role of women. They point out that in the field of engineering, for instance, there are far fewer women graduate students but more women faculty than in the field of economics.

One possible reason why economics may be different is that the relationship between graduate and undergraduate work in economics in the US is quite different than it is in other fields. As previously discussed, there tends to be a large disconnect between the US graduate education in economics, which tends to focus on abstract theory, techniques, and technical issues, and the US undergraduate education in economics, which focuses more on policy issues, simpler models, and problem solving. The reason is that only a small percentage of undergraduate economics majors in the US actually go on to do work in economics, and a much smaller percentage go on to do graduate work in economics. Thus, most undergraduate economics majors, especially those at the liberal arts school level, have not experienced what graduate economics education will be 
like. That tends not to be the case in many other fields, such as engineering, physics, statistics, or biology, where undergraduate and graduate work blend more closely together, so students coming into graduate programs know what to expect. This is less true in economics, even though there is more information about the nature of graduate economics than there was in the past.

\section{CONCLUSION}

The survey results show rather clearly that at these top US graduate schools, women are not well integrated into the economics programs. The reason why, however, seems not to be that women lack intellectual interest in economics; rather it seems to be that the current structure of the graduate economics program does not fit women's interests and in many ways works to undermine that interest. Essentially, our view is that the highly technical, theoretical, and mathematical core of graduate school training in economics, that often has only at best an indirect connection with the type of work that applied policy students will be doing once they graduate, seems to permanently turn women away from economics.

We are not saying that the system does not work. As Colander (2007) emphasizes, graduate education at these schools is highly successful, and both women and men in the programs are generally positive about their departments. However, the process that makes a core set of courses that often has little connection to the type of applied policy work that many economists do imposes a significant cost. It discourages many women (and men) with great creative promise from entering and continuing in economics. It seems to us that a more policy-driven, first-year core, designed to provide a foundation for future applied policy work, rather than the current technical, theoretically driven core that often only has tangential connections to the applied policy issues that interest these students, would make for better economists and for far more effective graduate training for both men and women. Whether the core structure of graduate economics programs will eventually change is unclear, but until it does, the charge that US graduate economics programs are not female friendly will continue to be justified.

David Colander, Department of Economics, Middlebury College, Middlebury, VT 05753, USA e-mail: Colander@Middlebury.edu

Jessica Holmes, Department of Economics, Middlebury College, Middlebury, VT 05753, USA e-mail: jholmes@middlebury.edu 


\section{ACKNOWLEDGMENTS}

We would like to thank Joanna Lahey for helpful comments.

\section{NOTES}

${ }^{1}$ Generally, 95 percent or more of the students taking the survey answered the questions, so the sample size for the various tables is approximately sixty-five women and 160 men. A further discussion of the survey methodology can be found in Colander (2005).

${ }^{2}$ The specific questions in the questionnaire related to the various tables are provided in the Appendix.

3 The students' perception that the difference in stress levels is not due to differing abilities is consistent with previous literature. Shulamit Kahn (1995) reports that there are few gender differences in grades in economics courses.

${ }^{4}$ Since 88 percent of women and 91 percent of men report receiving a fellowship in their first year of graduate study, it is unlikely that these differences stem from differences in financial aid packages.

${ }^{5}$ Equal proportions of men and women are involved in a relationship (65 percent and 66 percent, respectively).

${ }^{6}$ Or as one referee pointed out, these ideas may, in fact, be sown at the undergraduate level and reinforced in graduate school.

${ }^{7}$ Economists use the term hysteresis to describe situations where effects of past events persist and therefore an understanding of the past is crucial to understanding the present.

${ }^{8}$ One might speculate that the reason women students' job placements are not improved with the addition of more female faculty members is that female faculty have fewer useful contacts than their male counterparts, or, as Neumark and Gardecki (1998) suggest, recommendations from female dissertation chairs may carry less weight on the job market.

${ }^{9}$ The affirmative action push to admit women and US students may be external to the departments. Departments know that the Committee on the Status of Women in the Economic Profession tracks women's enrollments, and they may face pressure from university administrations that consider gender equality and the training of US students an important goal.

${ }^{10}$ Expectations concerning the results for US men and foreign women are not clear, since each group receives preferential treatment in one respect but is at a disadvantage in another. Thus it is unclear how the mismatch hypothesis would rank them. Moreover, comparing the two groups is made more difficult by cultural differences among countries. As one reviewer pointed out, "in order for foreign families to send their daughters to school outside their country, the daughters have to really excel much more than sons." This is because in many other countries, women's value in the labor market is valued even less than in the US, and/or they are less likely to think of economics as an appropriate field for women, especially in Asian countries, from where many of the women students come. It might also help to explain why foreign women are less likely to agree with the statement "economics is the most relevant field given my intellectual interest." They may go into whatever field gets them to a foreign graduate program.

11 We would like to thank a reviewer for pointing out this possibility to us. 


\section{REFERENCES}

Bell, Amy, Stephen Spencer, Emma Iserman, and Christine Logel. 2003. "Stereotype Threat and Women's Performance in Engineering." Journal of Engineering Education 92(4): $307-12$.

Berg, Helen and Marianne A. Ferber. 1983. "Men and Women Graduate Students: Who Succeeds and Why?" Journal of Higher Education 54(6): 629-48.

Colander, David. 2005. "The Making of an Economist Redux." Journal of Economic Perspectives 19(1): 175-98.

- 2007. The Making of an Economist Redux. Princeton, NJ: Princeton University Press.

Colander, David and Arjo Klamer. 1987. "The Making of an Economist." Journal of Economic Perspectives 1(2): 95-111.

Deaux, Kay and Timothy Emswiller. 1974. "Explanations of Successful Performance on Sex-Linked Tasks: What is Skill for the Male is Luck for the Female." Journal of Personality and Social Psychology 29(1): 80-5.

Deaux, Kay and Elizabeth Farris. 1977. "Attributing Causes for One's Own Performance: the Effects of Sex, Norms, and Outcome." Journal of Research in Personality 11(1): 59 - 72.

Ferber, Marianne A. 1988. "Citations and Networking." Gender and Society 2(1): 82-9.

Gilbert, Lucia, June M. Gallessich, and Sherri L. Evans. 1983. "Sex of Faculty Role Model and Students' Self-Perceptions of Competency." Sex Roles 9(5): 597-607.

Ginther, Donna and Shulamit Kahn. 2004. "Women in Economics: Moving Up or Falling Off the Academic Career Ladder?" Journal of Economic Perspectives 18(3): $193-214$.

Gneezy, Uri, Muriel Niederle, and Arlo Rustichini. 2003. "Performance in Competitive Environments: Gender Differences." Quarterly Journal of Economics 118(3): 1049-74.

Gneezy, Uri and Arlo Rustichini. 2004. "Gender and Competition at a Young Age." American Economic Review, Papers and Proceedings 94(2): 377-81.

Goldstein, Elyse. 1979. "Effects of Same-Sex and Cross-Sex Role Models on the Subsequent Academic Productivity of Scholars." American Psychologist 34(5): 407-10.

Haslehurst, Paula, Sandra Hopkins, and Michael Thorpe. 1998. "'Not Rewarding,' 'Not Relevant,' 'Not Interesting': Career Choices of Female Economics Students.' Economics and Labour Relations Review 9(1): 108-22.

Kahn, Shulamit. 1993. "Gender Differences in Academic Career Paths of Economists." American Economic Review, Papers and Proceedings 83(2): 52-6.

— 1995. "Women in the Economics Profession." Journal of Economic Perspectives 9(4): $193-206$.

Marx, David M. and Jasmin R. Roman. 2002. “Female Role Models: Protecting Women's Math Test Performance." Personality and Social Psychology Bulletin 28(9): 1183-93.

McDowell, John and Janet Smith. 1992. "The Effect of Gender-Sorting on Propensity to Coauthor: Implications for Academic Promotion." Economic Inquiry 31(1): 68-82.

McDowell, John, Larry Singell, Jr., and Mark Slater. 2006. "Two to Tango? Gender Differences in the Decisions to Publish and Coauthor." Economic Inquiry 44(1): 15368.

Neumark, David and Rosella Gardecki. 1998. "Women Helping Women? Role Model and Mentoring Effects on Female PhD Students in Economics." Journal of Human Resources 3(1): $220-46$.

Roberts, Tomi-Ann. 1991. "Gender and the Influence of Evaluations on Self-Assessments in Achievement Settings.” Psychological Bulletin 109(2): 297-308.

Roberts, Tomi-Ann and Susan Nolen-Hoeksema. 1994. "Gender Comparisons in Responsiveness to Others' Evaluations in Achievement Settings." Psychology of Women Quarterly 18(2): 221-40. 
Spencer, Stephen, Claude Steele, and Diane Quinn. 1999. "Stereotype Threat and Women's Math Performance." Journal of Experimental Social Psychology 35(1): 4- 28.

Steele, Claude. 1997. "A Threat in the Air: How Stereotypes Shape Intellectual Identity and Performance." American Psychologist 52(6): 613-29.

Whitley, Bernard E., Jr., Maureen C. McHugh, and Irene H. Frieze. 1986. "Assessing the Theoretical Models for Sex Differences in Causal Attribution of Success and Failure," in Janet S. Hyde and Marcia C. Linn, eds. The Psychology of Gender: Advances through Meta-Analysis, pp. 107-35. Baltimore: John Hopkins University Press.

\section{APPENDIX}

Since the wording of questions can affect the answer, in this Appendix we report the survey questions underlying the tables. The table numbers correspond to table numbers in the text, such that Appendix Table 2 shows questions for Table 2 in the text, and so on.

\section{Appendix Table 2}

How important were the following factors in your decision to do graduate work in economics?

(3. Very important; 2. Somewhat important; 1. Unimportant)

$\begin{array}{lllll}1 . & \text { Enjoyed undergraduate classes in economics } & 3 & 2 & 1\end{array}$

2. Desire to engage in policy formulation $\quad \begin{array}{lll}3 & 2 & 1\end{array}$

$\begin{array}{lllll}3 . & \text { Good grades in economics classes } & 3 & 2 & 1\end{array}$

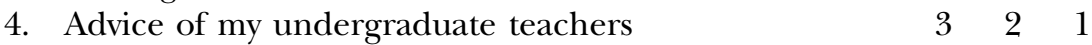

5. Acceptance by a good graduate school $\quad 3 \quad 2 \quad 1$

$\begin{array}{lllll}6 . & \text { Wanted to get a job in academia and economics } & 3 & 2 & 1\end{array}$ seemed to offer the best possibility

$\begin{array}{lllll}\text { 7. Economics seemed the most relevant field given my } & 3 & 2 & 1\end{array}$ intellectual interests

$\begin{array}{lllll}\text { 8. Political reasons } & 3 & 2 & 1\end{array}$

\section{Appendix Table 3}

Can you think of any elements of graduate school that have been, or are currently, stressful for you? Circle one.

(4. Very stressful; 3. Stressful; 2. Moderately stressful; 1. Not stressful)

Course work

Your financial situation

Relationships with faculty

Relationships with students

Doing the mathematics

Finding a dissertation topic

Maintaining a meaningful life outside graduate school

Conflict between course content and your interests

$\begin{array}{llll}4 & 3 & 2 & 1 \\ 4 & 3 & 2 & 1 \\ 4 & 3 & 2 & 1 \\ 4 & 3 & 2 & 1 \\ 4 & 3 & 2 & 1 \\ 4 & 3 & 2 & 1 \\ 4 & 3 & 2 & 1 \\ 4 & 3 & 2 & 1\end{array}$


Appendix Table 4

In which of the following activities, besides studying, are you currently engaged? (Check all applicable alternatives.)

[ ] Research assistantship

[ ] Teaching assistantship

[ ] Consulting

[ ] The writing of scholarly papers for publication

[ ] Political work

[ ] Volunteer work

[ ] Sports

[ ] Other significant activities. Please specify:

\section{Appendix Table 5}

What has been, or probably will be, the major factor in your choice of the dissertation topic? Check one.

[ ] The suggestion of a teacher

[ ] The desire to understand some economic phenomenon

[ ] The desire to get the dissertation done, and thus the feasibility of the topic

[ ] The application of certain mathematical or econometric techniques; the economic topic is of secondary importance

\section{Appendix Table 6}

Rate the following fields with respect to your degree of interest. Circle one. (3. Of great interest to me; 2. Of moderate interest to me;

1. Of no interest to me)

\begin{tabular}{|c|c|c|c|c|}
\hline Microtheory & 321 & Macrotheory & 321 & Econometrics \\
\hline Intern. Trade & 321 & Public Fin & 321 & Mon \& Banking \\
\hline Labor & 321 & Ind. Organ. & 321 & Law \& Econ \\
\hline Urban Econ & 321 & Econ Devel & 321 & Comp Econ Syst \\
\hline $\begin{array}{l}\text { Hist of } \\
\text { Thought }\end{array}$ & & Political Econ & 321 & \\
\hline
\end{tabular}

In which fields are you, or will you be, specializing? 


\section{Appendix Table 7}

Rank the following types of articles according to your interest. The journals are mentioned to give further indication of the type that is meant. ( 1 is most interesting, 2 is second, etc.)

An article on pure theory (cf. Journal of Economic Theory)

_ An article on pure econometrics (cf. Econometrica)

_ An article that combines theory and econometrics (cf. AER)

__ An article in applied economics (cf. Brookings Papers)

_ An article in non-conventional economics (cf. Rev. of Radical Pol. Ec.)

\section{Appendix Table 8}

Which characteristics will most likely place students on the fast track? Circle one.

(4. Very important; 3. Moderately important; 2. Unimportant;

1. I don't know)

Being smart in the sense that they are good at problem solving

Being interested in, and good at, empirical research $\quad \begin{array}{lllll}4 & 3 & 2 & 1\end{array}$

$\begin{array}{lllll}\text { Excellence in mathematics } & 4 & 3 & 2 & 1\end{array}$

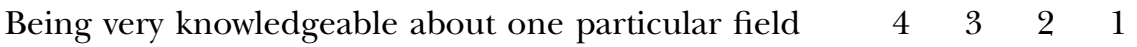

$\begin{array}{lllll}\text { Ability to make connections with prominent professors } & 4 & 3 & 2 & 1\end{array}$

$\begin{array}{lllll}\text { A broad knowledge of the economics literature } & 4 & 3 & 2 & 1\end{array}$

$\begin{array}{lllll}\text { A thorough knowledge of the economy } & 4 & 3 & 2 & 1\end{array}$

Other (specify) and comments:

\section{Appendix Table 9}

Will you pursue an academic career after graduate school?

Yes / No / Unsure

Where do you hope to be 15 years from now?

[ ] At a major university

[ ] At a good liberal arts college

[ ] At a major research institution

[ ] At an institution that is indirectly involved in economic policy making

[ ] In the private sector

[ ] Other. Specify: 
ARTICLES

Appendix Table 10

If you had to do it over again, would you go to graduate school in economics?

Yes / No / Unsure

Would you go to the same graduate school?

Yes / No / Unsure 